\title{
Erratum zu: Zum 80. Geburtstag von Prof. Dr. Georg Mattheß - Sonderbeiträge
}

\author{
Margot Isenbeck-Schröter
}

Online veröffentlicht: 5.2.2013

(C) Springer-Verlag Berlin Heidelberg 2013

\section{Erratum zu: Grundwasser - Zeitschrift der Fachsektion Hydrogeologie (2012) 17:193 \\ DOI 10.1007/s00767-012-0212-2}

Im Editorial, linke Spalte, 2. Absatz, Zeile 11, wurde versehentlich Herr Henning Holthusen als verstorbener Kollege genannt. Der korrekte Name an dieser Stelle ist: Herr Manfred Albertsen.
Die Autorin, die Editoren der Zeitschrift Grundwasser und die Vorstandsmitglieder der FH-DGG bedauern dieses Versehen außerordentlich und bitten in aller Form um Entschuldigung.

i.A. R. Kaufmann-Knoke

Redaktion der Zeitschrift Grundwasser

Die Online-Version des Originalartikels können Sie unter doi:10.1007/s00767-012-0212-2 finden.

M. Isenbeck-Schröter $(\bowtie)$

Universität Heidelberg, Heidelberg, Deutschland

E-Mail: Margot.Isenbeck@geow.uni-heidelberg.de 